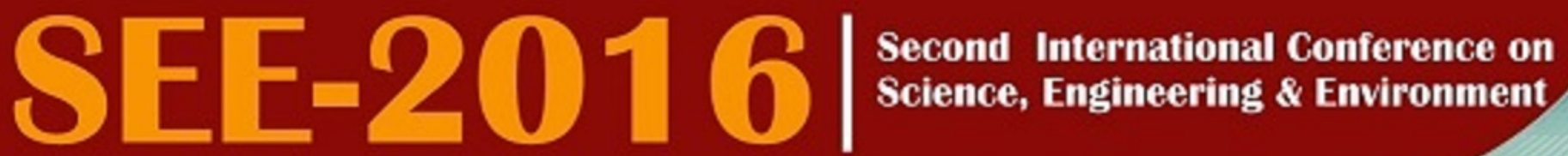
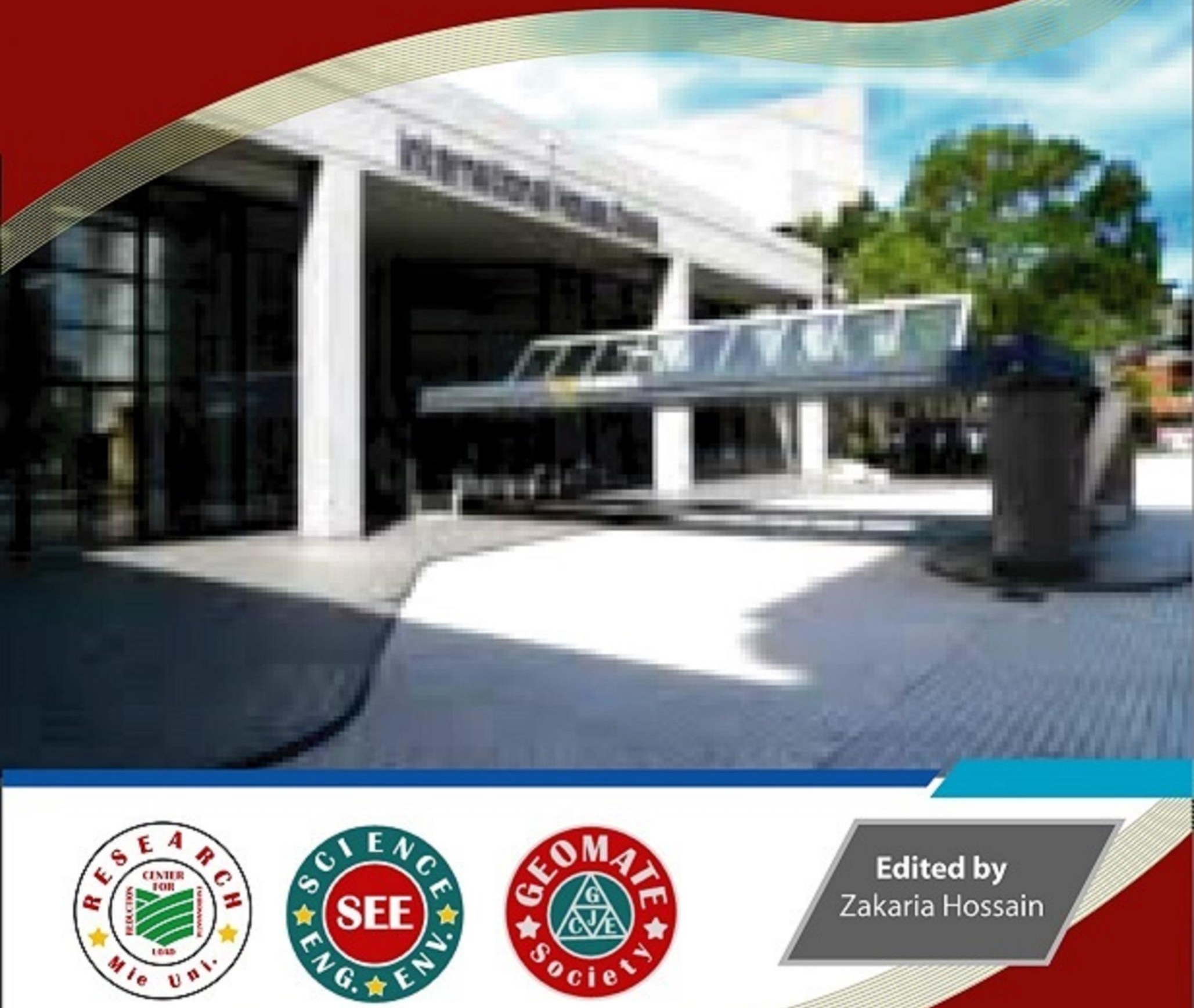

Edited by

Zakaria Hossain

21-23 November 2016

International Conference Center

Osaka JAPAN

ISBN: 978-4-9905958-7-6 C3051 


\title{
MECHANISM OF COAGULATION USING CHITOSAN FROM MYTILUS VIRDIS LINNEAUS SHELLS IN WATER TREATMENT
}

\author{
Sinardi ${ }^{1}$, Prayatni Soewondo ${ }^{2}$, Suprihanto Notodarmojo ${ }^{3}$, Cynthia Radiman ${ }^{4}$ \\ ${ }^{1}$ Bandung Institute of Technology, Doctoral Program Environmental Engineering Department, Bandung \\ 40132, Indonesia \\ Fajar University, Chemical Engineering Departement, Makassar, 90000, Indonesia \\ 2,3Bandung Institute of Technology, Environmental Engineering Departement, Bandung 40132, Indonesia \\ 4Bandung Institute of Technology, Chemistry Departement, Bandung 40132, Indonesia
}

\section{sinardi@unifa.ac.id}

\begin{abstract}
Green mussel (Mytilus viridis Linnaeus) is one of the shells from marine source that can be used as chitosan. On the other side of drinking water treatment using synthetic coagulant such us aluminum sulphate $\left(\mathrm{Al}_{2}\left(\mathrm{SO}_{4}\right)_{3}\right)$ concerns about the residual aluminum in the water that contains inorganic compounds are carcinogenic so it is necessary to do research about potential use of chitosan as a coagulant. This study conducted on laboratory-scale use of chitosan from green mussel shells as a coagulant in coagulation-flocculation process using turbid water from Tirtawening in Bandung City, Indonesia. The purpose of this study was to determine the mechanism of coagulation-flocculation process based on the characteristics of chitosan. Preparation of chitosan with deproteination process done using a solution of $\mathrm{NaOH} \mathrm{3.5 \%} \mathrm{10:} 1$ (v: w), stirring 2 hours $65^{\circ} \mathrm{C}$. Demineralization process using a solution of $\mathrm{HCl} 1 \mathrm{~N} \mathrm{15:} 1(\mathrm{v}: \mathrm{w})$, stirring 30 minutes $50{ }^{\circ} \mathrm{C}$. Deacetylation process using a solution $\mathrm{NaOH} 60 \% 20: 1$ (v: w) stirred 60 minutes $120^{\circ} \mathrm{C}$ produce chitosan with degree of deacetylation about $77.8 \%$ and molecular mass about $4,26 \times 10^{4} \mathrm{~g} / \mathrm{mol}$. The degree of deacetylation of chitosan effect ability formation of flock and the molecules of mass of chitosan effect in binding colloids in turbid water into one and form a flock large. The results concluded that chitosan from green mussel shells can be used as a coagulant for turbidity removal in water treatment and use it safe for the environment and health because from natural compounds and biodegradable.
\end{abstract}

Keywords: Mytilus viridis Linnaeus, Chitosan, Degree of Deacetylation, Molecular of Mass, CoagulationFlocculation, Turbid Water, Turbidity Removal

\section{INTRODUCTION}

Human consciousness about the importance of health led to the need for clean water increases. But the problem of clean water availability decreased mainly quality, the most common problem encountered is the turbidity of the water. Turbidity is caused by the presence of organic and inorganic materials are suspended and dissolved, as well as inorganic and organic materials in the form of plankton and other microorganisms contained in water. Turbidity in the water treatment process can be eliminated through the process of coagulation.

Coagulation is one process of the water treatment to improve the quality of water produced. Coagulation process aims to eliminate the solute to be precipitated by adding a chemical compound into the water resulting in the incorporation of particles that are difficult to settle and form a flock.

Until now, the polymer coagulant derived from synthetic are commonly used type of coagulant. In between the two types of the coagulant, the coagulant is a synthetic material that is widely used in water treatment processes, in addition to more easily obtained, from an economic point of relatively cheaper price. But the use of synthetic coagulant excess it undesirable effects on the environment and health as a coagulant of this type is not biodegradable. This is the basis of the researchers focused on the use of natural coagulants such as chitosan is a solution that can be used as a coagulant derived from natural materials [1].

The process of coagulation is the charge neutralization process by adding a coagulant or chemical, while coagulation is to destabilize the process of agglomeration of the particles to form a flock becomes larger and easier to settle [2]. With the addition of coagulant, the colloidal stability in disturbed water as coagulant will stick to the surface of colloidal and change their electrical charge to form aggregates which can be precipitated [3].

Chitosan is a chitin derivative obtained by deacetylation process, a cationic polymer which is biodegradable. Chitosan can substitute synthetic coagulants in water treatment with the advantages: (1) residual coagulant is not harmful to human health because it is an organic material, (2) generate sludge biodegradable, and (3) can be made using the waste 
of fishery products [4].

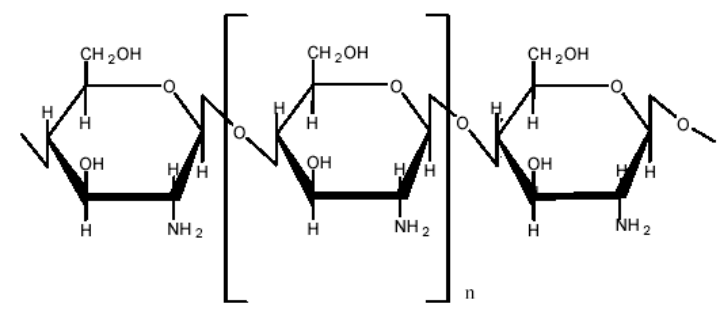

Figure1. Structure Molecule of Chitosan

Chitosan is a biopolymer obtained by deacetylation of chitin contained in some marine shells [5]. Amine groups (NH2) on chitosan (see Figure.1) is a strong nucleophile that can be used as a polyelectrolyte that has many functions and is more reactive than chitin.

\section{MATERIAL AND METHODS}

\section{Chitosan}

Chitosan was extracted from Mytilus viridis linnaeus shells prepared using Knorr method with some modifications [6]. Preparation of chitosan with deproteination process done using a solution of $\mathrm{NaOH} 3.5 \%$ 10: 1 (v: w), stirring 2 hours $65^{\circ} \mathrm{C}$. Demineralization process using a solution of $\mathrm{HCl} 1 \mathrm{~N}$ 15: 1 (v: w), stirring 30 minutes $50{ }^{\circ} \mathrm{C}$. Deacetylation process using a solution $\mathrm{NaOH}$ 60\% 20:1 (v: w) stirred 60 minutes $120^{\circ} \mathrm{C}$. Chitosan produced has characteristics of the degree of deacetylation was $77.80 \%$ and a molecular mass was $4,26 \times 10^{4} \mathrm{~g} / \mathrm{mole}$.

\section{Turbid Water}

This study uses turbid water from the outlet unit PDAM Tirtawening in Bandung, Indonesia. The characterization of raw water can be seen in the Table.1 below.

Table 1 Physical and Chemical of Turbid Water

\begin{tabular}{llcccccc}
\hline $\mathrm{pH}$ & Turbid & Conduct & TSS & TDS & OM & Fe & $\mathrm{Mn}$ \\
\hline 6.73 & 30.10 & 110.83 & 25 & 77.77 & 1 & 0.34 & 0.05 \\
\hline Total Suspended Solid & & & & & & \\
Total dissolved solids \\
Organic Matter \\
Turbidity, NTU; Conductivity, $\mu \mathrm{S} / \mathrm{cm}$; all concentrations are in $\mathrm{mg} / \mathrm{L} . ; \mathrm{pH}$ were \\
determined by the author
\end{tabular}

\section{Dissolution Chitosan}

Dissolution of chitosan following the method [7] of $1 \mathrm{~g}$ chitosan was dissolved in $100 \mathrm{~mL}$ of $1 \%$ acetic acid ( $\mathrm{v} / \mathrm{v}$ ) to obtain $10 \mathrm{mg}$ of chitosan in $1 \mathrm{~mL}$ of solution $(1 \% \mathrm{w} / \mathrm{v})$. Stirring chitosan solution using a magnetic stirrer for 6 hours to ensure perfect chitosan dissolved. With this dissolution, $100 \mathrm{ml}$ of acetic acid solution $1 \%(\mathrm{v} / \mathrm{v})$ then obtained $1000 \mathrm{mg}$ $/ \mathrm{ml}$ of chitosan in solution.

\section{Jar Test}

Research conducted in batches in a laboratory scale using jar test, which is also the operational simulation of conventional treatment processes.

1. Jar test use Flocculation SW1 Stuart Scientific, using a beaker containing $500 \mathrm{~mL}$ of turbid water.

2. Stirring rapidly performed at $100 \mathrm{rpm}$ for 1 minute after the addition of coagulant, followed by slow mixing at $60 \mathrm{rpm}$ for 10 minutes.

3. After the flocculation process is completed, flock had formed allowed to settle for 30 minutes, separated from the flock, turbid water and then analyze.

\section{RESULTS AND DISCUSSION}

\section{Effect of the Chitosan Dosage}

Chitosan coagulant dosage effect on the amount for turbidity removal that occur after the coagulation process, as seen in the results of tests conducted jar in Figure.2. Turbidity removal increased with increasing dosage of chitosan, but the addition of coagulant dosage showed excessive turbidity removal which does not different much even decline, this is due to the failure of flock formation and saturation of chitosan aside turbidity.

In addition to turbidity, $\mathrm{pH}$ is a very important parameter in the coagulation process, because it can affect the $\mathrm{pH}$ of the surface charge of the colloidal molecules, the charge of the functional groups of organic material contained in the charge of water and other components dissolved in water. At high $\mathrm{pH}$ (alkaline), colloid-containing organic compounds will be ionized due to the carboxyl groups of chitosan will lose a proton (due react with alkali), as well as the positive charge of coagulant required to neutralize the charge of colloids will also be reduced. As a result, the required dosage of coagulant will also increase at higher $\mathrm{pH}$.

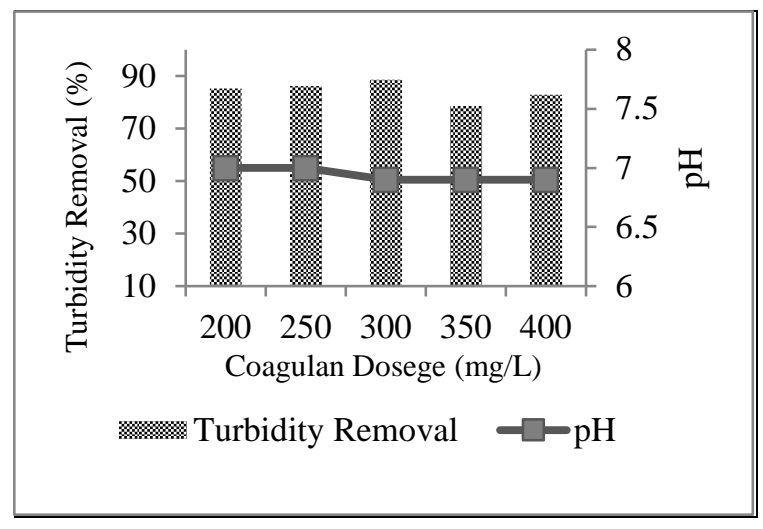

Figure2. Turbidity Removal using Chitosan 
Provision for turbidity using chitosan as a coagulant optimum dose of $300 \mathrm{mg} / \mathrm{L}$ of $88.60 \%$ and pH 6.73 to 6.9 after coagulation. At higher coagulant dosage higher concentrations are 350 and $400 \mathrm{mg} / \mathrm{L}$ allowance for the lower turbidity, is due at the dose of chitosan as cationic polyelectrolyte becomes saturated. The result will damage the bridge between the particles so that not all of the colloidal particles can be deposited.

\section{Mechanism of Coagulation}

Mechanism of coagulation using chitosan in water treatment due to chitosan cannot react with water because of the hydrogen bonds that are formed are very weak. So that the $\mathrm{OH}$ and $\mathrm{NH}_{2}$ owned makes chitosan is alkaline. The amine group attached to the $\mathrm{C}$ atom, while the primary hydroxyl groups attached directly to a carbon atom other and bonded to the secondary hydroxyl amine group.

Chitosan can be used as a coagulant that is more effective and efficient than the use of alum in the process of coagulation, evident from the reduced turbidity of river water with the use of chitosan in the chitosan concentration is low [8]. Coagulation process using chitosan flocculation can decrease inorganic and organic particles suspended and dissolved organics contained in water [9].

Mechanism of coagulation using chitosan was when the polymer molecules into contact with the colloidal particles, then some of chitosan groups adsorbed on the surface of the particle and the rest remain in solution. Furthermore, the particles will be attached to another part of the polymer chain which serves as a bridge that can confine the particles and form flocks larger so as to bring the particles together down and deposited polymer. In acidic conditions, the amino group $\left(-\mathrm{NH}_{2}\right)$ chitosan will catch $\mathrm{H}^{+}$from the environment so that the amino group protonated be $-\mathrm{NH}_{3}{ }^{+}$and then chitosan acts as a salt that can be dissolved in water.

Associated with the mechanism of coagulation, colloidal chitosan can bind into flock by two methods, namely the charge neutralization and bridge colloid polymer [10]. Chitosan with a large molecular mass means having long-chain polymer colloids will bind together and form large flocks. $\mathrm{NH}_{2}$ group in the chitosan will catch $\mathrm{H}^{+}$in water and form a group $\mathrm{NH}_{3}{ }^{+}$. This group will neutralize the negative charge of colloid and polymer chain of chitosan will catch colloids into a single unit see Figure.3 below.

Chitosan is a cationic polyelectrolyte and longchain polymer, has a large molecular mass and reactive because of the amine and hydroxyl groups which act as electron donors. Due to the properties of the regular chitosan interacts with the colloidal particles contained in the water through the bridge between flock particles (coagulation) [11] and [12]. To simplify the process of coagulation, the chitosan dissolved in advance by using acid to obtain a solution of chitosan. The mechanism is based on the properties of the chitosan-containing amine group which reacts with the acid when it will form a salt. Therefore it must be dissolved into the acidic chitosan.

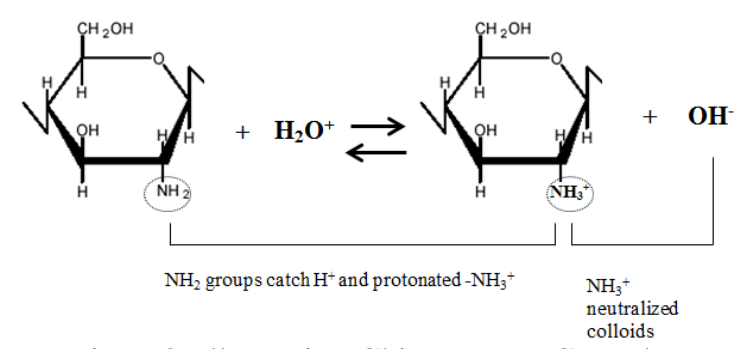

Figure3. Illustration Chitosan as a Coagulant

Amino groups of chitosan $\left(\mathrm{NH}_{2}\right)$ in a solution of making the chitosan is positively charged (indicated as a polyelectrolyte cationic) so attractive for flocculation and application of binding different that allow molecules binding different that allows the molecules bind to the surface of the negatively charged through the binding of ionic or hydrogen [13].

The mechanism of coagulation and flocculation of chitosan, beginning with the charge neutralization colloid charge neutralization in turbid water, amine containing a lone pair on the nitrogen atom, the amine is alkaline (Bronsted-Lowry) and nucleophiles character. Then the bridge is formed between the particles form a flock colloids, the chitosan polymer chain of chitosan increasingly charge (-) colloidal neutralized by $\mathrm{NH}_{3}{ }^{+}$group see Figure 4 . The chitosan polymer colloids catch into a single unit to form larger aggregates so easy to settle.

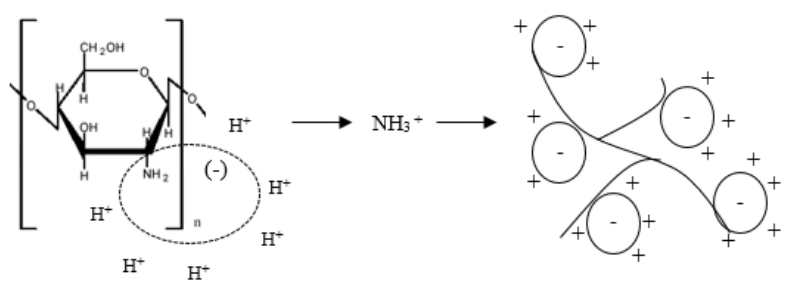

Figure 4. Illustration Coagulation and Flocculation Process Using Chitosan

SEM images in Figure. 5 shows the surface of the slab-shaped chitosan large and stringy. While the surface of the flock formed has a solid surface and porosity smaller, it shows that during the process of coagulation merger colloidal particles which are then attached to the surface of chitosan. SEM on chitosan and flock that is formed can be known before the change of the surface structure of chitosan is used as a coagulant and after the coagulation process. 

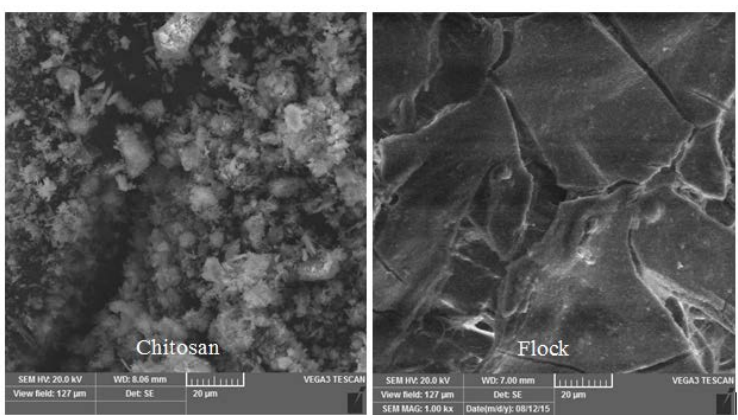

Figure5. Scanning Electron Microscope (SEM) of Chitosan and Flock Formed after Coagulation

Changes in the surface structure of chitosan and chitosan flock occurs because of the addition of the turbid water in water treatment caused colloidal particles will come closer together and the collisions between colloidal particles and alter its cargo into neutral, causing clumping and forming flock.

\section{CONCLUSION}

Chitosan from Mytilus viridis linnaeus shells can be used as a coagulant to substitute synthetic coagulant in water treatment because it has the ability for turbidity removal. The ability of chitosan aside turbidity because it has a large molecular mass so long chitosan polymer molecule chains that play a role in the neutralization of the charge of colloids and polymers as a bridge that has the ability to bind and precipitate colloids into flock.

\section{ACKNOWLEDGEMENTS}

The authors gratefully acknowledge the financial support received in the form of Dissertation Research Grant from Ministry of Research, Technology and Higher Education in Indonesia.

\section{REFERENCES}

[1] Yang, Z, Yabo Shang, Yaobo Lu, Yichun Chen, Xin Huang, Aimin Chen, Yuxiang Jiang, Wei Gu, Xiaozhi Qian, Hu Yang, dan Rongshi Cheng, Flocculation Properties of Biodegradable Amphoteric Chitosan-Basen Flocculants, Chemical Engineering Journal, 172, (2011) 287-295.

[2] Hammer, M. J, Water Supply \& Polluti on Control 7th Edition, Pearson Prentice Hall, United States of America, 2005.
[3] Eckenfelder, W. J, Industrial Water Poluttion Control, Third edition,. Mc Graw-Hill Company, Singapore, 2000.

[4] Pan, J.R, Chihpin Huang, Shuchuan Chen, and Ying Chien Chung, Evaluation of a Modified Chitosan Biopolymer for Coagulantion of Colloidal Particles, Physicochemical and Engineering Aspects, 147, (1998) 359-364.

[5] Marganof. Potensi Limbah Udang Sebagai Penyerap Logam Berat (Timbal, Kadmium dan Tembaga) di Perairan. Information on http://rudict.topcities.com/pps70271034/margonof.html

[6] Sinardi, Soewondo P, Notodarmojo S, and Radiman C, The Degree of Deacetylation Chitosan Various Marine Shells, International Journal of Applied Engineering Research, (2014) 18047-18051.

[7] Danwanichakul, P., Werathirachot, R., Kongkaew, C., and Loykulnat, S, Coagulation of Skim Natural Rubber Latex Using Chitosan or Polyacrylamide as an Alternative to Sulfuric Acid, European Journal of Scientific Research, Volume 62 No. 4, (2011) 537-547.

[8] Mu'minah, Aplikasi Kitosan Sebagai Koagulan untuk Penjernihan Air Keruh, Program Studi Kimia, FMIPA. Institut Teknologi Bandung. Indonesia, 2008.

[9] Renault, F, B. Sancey, P.M Badot, dan G. Crini, Chitosan for Coagulations/Flocculation Processes-An Eco-Friendly Approach, European Polymer Journal, Volume 45, Issue 5, (2008) 1337-1348.

[10] Tripathy, Tridiband De, and Bhudeb R, Flocculation: A New Way to Treat the Waste Water, Journal of Physical Sciences, Volume 10, (2006) 93-127.

[11] Chung GH, K. B, Physicochemical Properties of Chitin andChitosan Prepared from Lobster Shrimp Shell, Korean Journal Food Science Technology, 28, (1996) 870-876.

[12] Prashanth KVH and Tharanathan RN, Chitin/Chitosan: Modification and Their Unlimited Application Potential an Overview, Journal Food Science Technology, 18, (1997) 17-131.

[13] Hasan M.A, and Mohd Hafiz Puteh, PreTreatment of Palm Oil Mill Effluent (POME): Comparison Study Using Chitosan and Alum, Malaysian Journal of Civil Engineering, (2007) 19:2. 